\title{
Evaluation of standard and regional satellite chlorophyll-a algorithms for moderate-resolution imaging spectroradiometer (MODIS) in the Bohai and Yellow Seas, China: a comparison of chlorophyll-a magnitude and seasonality
}

Yueqi Wang, Dongyan Liu, Yujue Wang, Zhiqiang Gao \& John K. Keesing

To cite this article: Yueqi Wang, Dongyan Liu, Yujue Wang, Zhiqiang Gao \& John K. Keesing (2019) Evaluation of standard and regional satellite chlorophyll-a algorithms for moderateresolution imaging spectroradiometer (MODIS) in the Bohai and Yellow Seas, China: a comparison of chlorophyll-a magnitude and seasonality, International Journal of Remote Sensing, 40:13, 4980-4995, DOI: 10.1080/01431161.2019.1577579

To link to this article: https://doi.org/10.1080/01431161.2019.1577579

\section{Published online: 15 Feb 2019.}

\section{Submit your article to this journal $\llbracket$}

Џll Article views: 138

Q View related articles $\sqsubset$

View Crossmark data ¿ 


\title{
Evaluation of standard and regional satellite chlorophyll-a algorithms for moderate-resolution imaging spectroradiometer (MODIS) in the Bohai and Yellow Seas, China: a comparison of chlorophyll-a magnitude and seasonality
}

\author{
Yueqi Wang ${ }^{a, b}$, Dongyan Liu ${ }^{a, b, c}$, Yujue Wang ${ }^{a, b}$, Zhiqiang Gao ${ }^{a, b}$ and John K. Keesing ${ }^{d}$ \\ ${ }^{a}$ CAS Key Laboratory of Coastal Environmental Processes and Ecological Remediation, Yantai Institute of \\ Coastal Zone Research (YIC), Chinese Academy of Sciences (CAS), Yantai, P. R. China; 'bShandong Key \\ Laboratory of Coastal Environmental Processes, YICCAS, Yantai Shandong, P. R. China; 'State Key \\ Laboratory of Estuarine and Coastal Research, East China Normal University, Shanghai, P. R. China; ${ }^{\text {Indian }}$ \\ Ocean Marine Research Centre, CSIRO Oceans and Atmosphere Research and University of Western \\ Australia Oceans Institute, Crawley, Australia
}

\begin{abstract}
Retrieval of satellite remotely sensed chlorophyll-a (chl-a) concentrations in coastal regions such as the Bohai and Yellow Seas (BYS) is challenging due to their complex oceanic and atmospheric optical properties. The standard OC3M (ocean chl-a three-band algorithm for MODIS (moderate-resolution imaging spectroradiometer)) algorithm has been widely used in the BYS, despite well-known uncertainties about its accuracy in terms of absolute magnitude. This was based on the belief that OC3M chl-a is capable of representing reliable relative spatial and temporal patterns of sea surface chl-a concentrations. In this study, the ability of the standard OC3M chl-a algorithm to reproduce accurate seasonality patterns was evaluated, based on comparisons with in situ chl-a measurements in the BYS. The results quantified the overestimation by the standard OC3M algorithm with a median absolute percentage difference of $98.48 \%$ and a median relative difference of $1.13 \mathrm{mg} \mathrm{m}^{-3}$.More importantly, the seasonality from OC3M chl-a was significantly biased relative to the seasonal patterns of in situ chl-a. In addition, a regional GAM (generalized additive model)-based satellite chl-a algorithm was evaluated and compared with OC3M chl-a. The results showed the GAM chl-a improved accuracy in both magnitude and seasonality when compared with in situ chl-a, relative to that from OC3M chl-a.
\end{abstract}

\section{ARTICLE HISTORY}

Received 24 April 2018

Accepted 27 November 2018

\section{Introduction}

Chlorophyll-a (chl-a) concentration has long been regarded as a powerful way of representing phytoplankton biomass in the ocean (Richards and Thompson 1952; Ryther and Yentsch 1957). In recent decades, remotely sensed satellite ocean colour products have been widely used to detect synoptic spatial and temporal patterns and

CONTACT Yueqi Wang yueqiwang@yic.ac.cn $\bigotimes$ Yantai Institute of Coastal Zone Research, CAS, 17th Chunhui Road, Laishan District, 264003, Yantai, China 
variability of sea surface chl-a concentrations (Gregg et al. 2003; Siegel et al. 2013). However, when applied to coastal waters which are shallow in depth and/or have high turbidity, satellite-derived chl-a may produce significant biases due to inaccuracies in atmospheric correction models and improper inversion algorithms (Melin, Zibordi, and Berthon 2007; Odermatt et al. 2012; IOCCG 2000). Therefore, careful evaluation of the existing satellite chl-a algorithms and developing new regional algorithms are essential for satellite ocean colour applications over optically complex waters.

The Bohai and Yellow Seas (BYS), located in northern China, are connected by the Bohai Strait (Figure 1(a)). Most of the BYS consists of a shallow continental shelf (water depth $<100 \mathrm{~m}$ ). The optical properties of BYS are significantly influenced by high suspended sediment from numerous river discharges and bottom reflectance from the shallow sea floor (Wang, Tang, and Shi 2007; Shi and Wang 2012; Cui et al. 2014), which

(b)

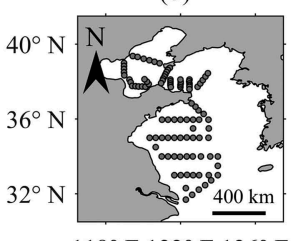

$118^{\circ} \mathrm{E} 122^{\circ} \mathrm{E} 126^{\circ} \mathrm{E}$ (c)

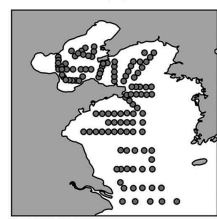

(d)

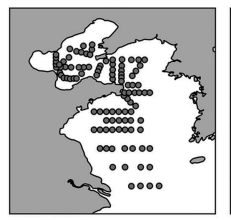

(a) (e)

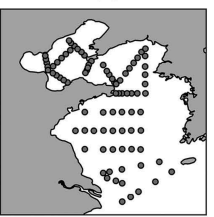

(f)

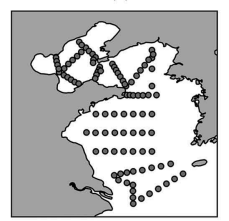

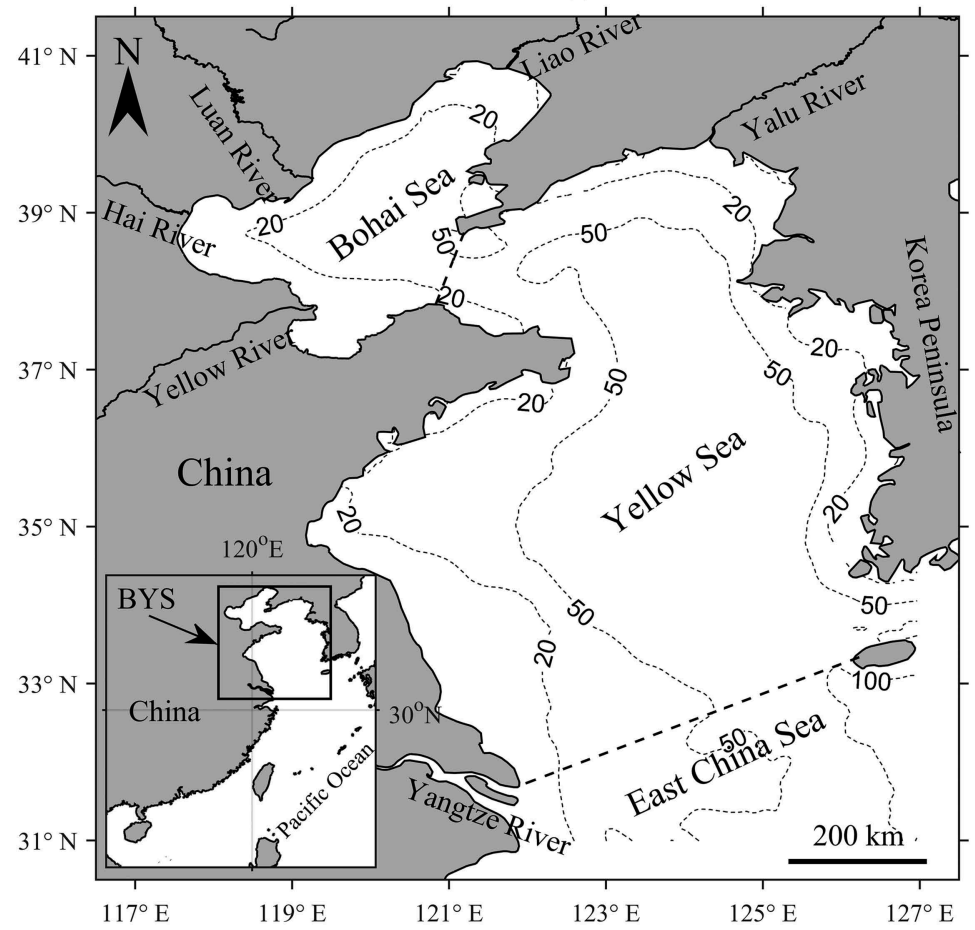

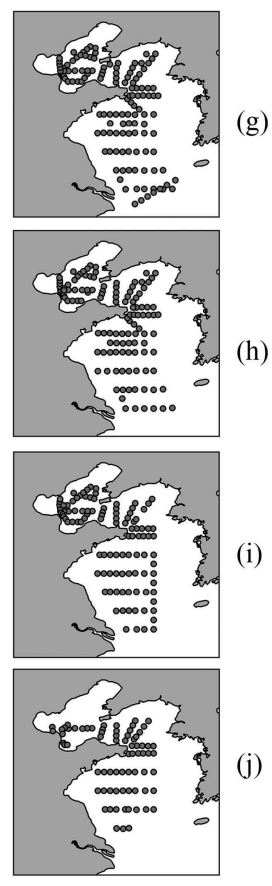

(g)

(i)

(j)

Figure 1. (a) Map of the BYS and (b)-(j) the sites of the in situ chl-a measurements during each cruise. (b) 20 April-4 May 2010; (c) 2 May-20 May 2012; (d) 2 November-19 November 2012; (e) 22 June-9 July 2013; (f) 6 November-24 November 2013; (g) 28 April-18 May 2014; (h) 7 November-23 November 2014; (i) 17 August-5 September 2015; (j) 15 January-30 January 2016. The $20 \mathrm{~m}$ and $50 \mathrm{~m}$ isobaths are also shown as contours in (a). 
leads to large errors in satellite chl-a derived using the standard algorithms (Shi and Wang 2010; Siswanto et al. 2011). Previous studies have concentrated on improving the quality of satellite chl-a through various schemes, including application of better atmospheric correction models to acquire more accurate reflectance information (Son, Wang, and Shon 2011), tuning default parameters in the standard chl-a models (Shang et al. 2014; Siswanto et al. 2011), and developing new chl-a inversion models based on new optical features (Siswanto et al. 2011; Chen and Quan 2013). At present, however, there is still no conclusion about which chl-a product is the most appropriate for application in the BYS. To date, the standard chl-a algorithm has been the primary choice for analysing chl-a dynamics in the BYS due to easy accessibility and because results can easily be compared with previous literature (Fu, Xu, and Liu 2016; Liu and Wang 2013; Yamaguchi et al. 2012). However, in order to acquire reliable chl-a dynamics from the standard chl-a products, some compromises had to be made in their application in the BYS. For instance, only the relative patterns were compared in some studies ( $\mathrm{Fu}, \mathrm{Xu}$, and $\mathrm{Liu}$ 2016; Liu and Wang 2013), while some other studies confined analysis to chl-a variations in summer and spring when the standard satellite chl-a has relatively high accuracy (Yamaguchi et al. 2013, 2012).

When concentrating on determining the seasonality of chl-a, the standard remotely sensed ocean colour products have been commonly assumed to be valid representation in the BYS (Zhang et al. 2017; Fu, Xu, and Liu 2016; Liu and Wang 2013). However, to our knowledge, there has been no defining evaluation of whether the standard remotely sensed products derive reliable information on chl-a seasonality over such complex waters. To address this question, we collected in situ sea surface chl-a measurements on nine cruises over 7 years, with extensive spatial and seasonal coverage. In this study, we aim to evaluate the performance of the standard OC3M (ocean chl-a three-band algorithm for MODIS (moderate-resolution imaging spectroradiometer)) chl-a algorithm in its capability to retrieve chl-a values that enable reliable seasonal dynamics to be determined. In addition, a regional statistical chl-a algorithm based on a generalized additive model (GAM) we reported previously (Wang, Liu, and Tang 2017) was compared with in situ chl-a measurements and the standard OC3M-derived chl-a. The GAM chl-a product provides a new insight into the chl-a seasonality of the BYS, and we discuss the underlying factors driving sea surface chl-a synoptics.

\section{Data and methods}

\subsection{In situ measurements of $\mathrm{chl}-\mathrm{a}$}

In situ sea surface chl-a dataset was used for the validation of the remotely sensed chl-a data. These in situ samples were collected from nine cruises conducted during the years 2010-2016 (Figure 1(b-j)). These cruises used the same sampling and analysis methods for chl-a concentration. Three duplicate samples of $1000 \mathrm{ml}$ of seawater were collected using Niskin bottles from a depth of $<5 \mathrm{~m}$ and then filtered through $47 \mathrm{~mm}$ Whatman GF/F (Glass Fiber/F) filters under low vacuum. The filters were kept in the dark at $-20^{\circ} \mathrm{C}$ before laboratory analysis. In the laboratory, photosynthetic pigments were extracted with $15 \mathrm{ml}$ of $90 \%$ acetone in the dark for $24 \mathrm{~h}$ at $4^{\circ} \mathrm{C}$ (Lorenzen 1967) and the chl-a concentration was determined spectrophotometrically (TU-1800, Persee, China). 


\subsection{Satellite chl-a data}

The daily MODIS/Aqua standard local area coverage (LAC) remote-sensing reflectance $\left(R_{\mathrm{rs}}\right)$ images for 10 available visible bands (wavelength at $412 \mathrm{~nm}, 443 \mathrm{~nm}, 469 \mathrm{~nm}, 488 \mathrm{~nm}$, $531 \mathrm{~nm}, 547 \mathrm{~nm}, 555 \mathrm{~nm}, 645 \mathrm{~nm}, 667 \mathrm{~nm}$, and $678 \mathrm{~nm}$ ) were downloaded from the NASA (National Aeronautics and Space Administration) Goddard Space Flight Center's oceancolor website (NASA oceancolor 2017).The $R_{\mathrm{rs}}$ datasets were derived using standard calibration and atmospheric correction algorithms (Gordon 1997; Wang and Shi 2007), with a spatial resolution of approximately $1 \mathrm{~km} \times 1 \mathrm{~km}$ and over the time span from 4 July 2002 to 31 December 2016. The standard OC3M chl-a product was calculated using a fourth-order empirical algorithm based on two MODIS $R_{\mathrm{rs}}$ band ratios $\left(R_{\mathrm{rs}}(443) / R_{\mathrm{rs}}(547)\right.$ and $R_{\mathrm{rs}}(488) / R_{\mathrm{rs}}$ (547)) (O'Reilly, Maritorena, and Siegel 2000). A regional GAM chl-a algorithm developed by Wang, Liu, and Tang (2017) was also applied to generate a new chl-a product for comparison. Briefly, the GAM chl-a algorithm was constructed as a stable nonlinear smoothed regression based on the GAM, with the in situ chl-a as a response and the MODIS visible $R_{\mathrm{rs}}$ bands (wavelength at $412 \mathrm{~nm}, 443 \mathrm{~nm}, 469 \mathrm{~nm}, 488 \mathrm{~nm}, 531 \mathrm{~nm}, 547 \mathrm{~nm}, 555 \mathrm{~nm}, 645 \mathrm{~nm}$, $667 \mathrm{~nm}$, and $678 \mathrm{~nm}$ ) and the water depth as predictors.

\subsection{Methods for satellite chl-a data validation}

The performance of the satellite chl-a algorithms (i.e., OC3M and GAM) was assessed in four ways:

(1) The satellite chl-a values were extracted and compared against the coincident in situ chl-a measurements. For extracting concurrent data from satellite images and in situ measurements, a criterion similar to that introduced in Son, Wang, and Shon (2011) and Wang, Son, and Shi (2009) was used: (i) a time difference of $\pm 24 \mathrm{~h}$ was set to acquire matching pairs due to limited match-ups; (ii) the median value from a 5 pixels $\times 5$ pixels window centred at each in situ site was extracted from the satellite images to define the coincident remotely sensed values; (iii) to minimize the sensor and/or algorithm noise and avoid strong non-homogeneous windows, the satellite data were only used when the number of valid pixels in the 5 pixels $\times 5$ pixels window exceeded 15 and the coefficient of variation (CV) was less than 0.15 . As a result, a concurrent dataset with 209 matching pairs between satellite and in situ measurements was produced for statistical analyses. The accuracy of satellite chl-a estimates was evaluated using the median absolute percentage difference (MAPD) and the median relative difference (MRD), calculated, respectively, as:

$$
\begin{gathered}
\operatorname{MAPD}(\%)=\operatorname{median}\left|\frac{C_{i}^{\text {sa }}-C_{i}^{\text {in }}}{C_{i}^{\text {in }}}\right|, i=1,2,3, \ldots \ldots, N \\
M R D=\operatorname{median}\left(C_{i}^{\text {sa }}-C_{i}^{\text {in }}\right), i=1,2,3, \ldots \ldots, N
\end{gathered}
$$

where $N$ is the number of match-ups, $C^{\text {sa }}$ is the satellite-derived $c h l-a$, and $C^{\text {in }}$ is the in situ measured chl-a. MAPD describes the overall uncertainty and MRD gives the 
direction of bias (i.e., overestimation or underestimation) in satellite chl-a estimates with respect to in situ chl-a measurements. In addition, scatter plots of in situ chl-a measurements versus satellite chl-a estimates from OC3M and GAM algorithms were generated, and the linear regression fitted on log-transformed data. From these, the corresponding slope, intercept, and coefficient of determination $\left(R^{2}\right)$ were obtained.

(2) Visual inspections of spatial differences between in situ results and the corresponding satellite chl-a maps were carried out. The in situ measured chl-a for each cruise was plotted as spatially distributed colour scatters with colour scales representing chl-a values. The satellite chl-a map for each cruise was a composite map of all the daily satellite chl-a images during the period of the cruise carrying out. In addition, the spatial chl-a average of each of the in situ measured and satellite-derived maps were calculated, resulting in three chl-a time series (i.e., in situ, OC3M and GAM) with nine samples for each. Time-series comparisons and correlation analyses were performed between the in situ chl-a averages against the OC3M and GAM chl-a averages, respectively.

(3) The BYS was subdivided into three subregions on the basis of isobaths, including a coastal region ( $<20 \mathrm{~m}$ isobath), an offshore region ( $>50 \mathrm{~m}$ isobath), as well as a transitional region (between 20 and $50 \mathrm{~m}$ isobaths) (Figure 1(a)). The monthly averaged satellite chl-a series and in situ chl-a averages were calculated and compared for each subregion as well as for the entire BYS.

(4) The 5 days' composite (pentad) climatological chl-a series for the specific regions were calculated and compared with the corresponding in situ chl-a series. Here, the 5 days' climatological value was calculated as the median of all the valid data over each time span during the years 2010-2016. The in situ chl-a averages were overlaid on the pentad climatological chl-a series according to their calendar date. Then, time-series comparisons and correlation analyses were carried out between matching satellite and in situ chl-a series over each region.

In this study, all the averages were calculated as a median. We used medians rather than arithmetic means because medians are more robust with respect to outliers and closer to modal values considering the typical log-normal, rather than normal distribution of the chl-a concentrations (Campbell 1995). In addition, the correlation analysis between satellite and in situ chl-a was performed using the Spearman's rank correlation coefficient (non-parametric statistical test) due to the log-normal distribution of chl-a.

\section{Results}

\subsection{Statistical comparisons}

The overall performance of the OC3M and GAM chl-a estimates compared with in situ chla measurements was evaluated (Figure 2). Figure 2(a,b) show the scatter plots and the corresponding statistic indicators of the in situ measured chl-a versus the OC3M and GAM chl-a estimates, respectively. The standard OC3M algorithm which was developed and optimized for open ocean waters performed poorly in the BYS, with a high MAPD value of $98.48 \%$ (Figure 2(a)). The MRD value of $1.13 \mathrm{mg} \mathrm{m}^{-3}$ (Figure 2(a)) indicates a distinct 
(a)

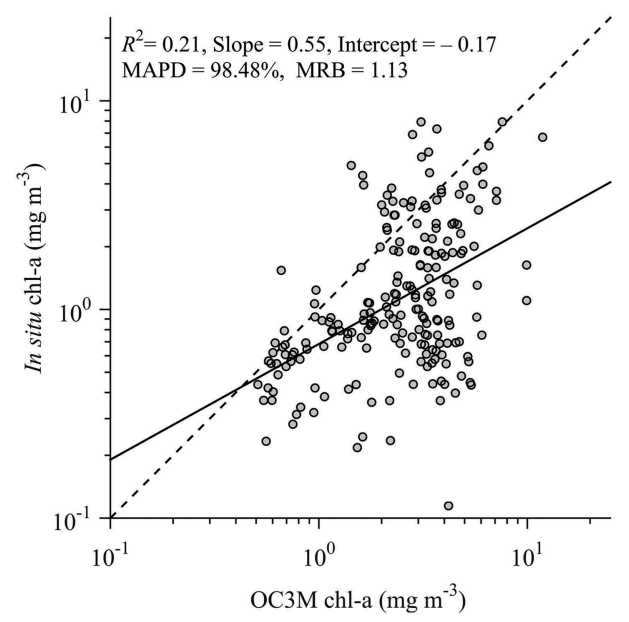

(b)

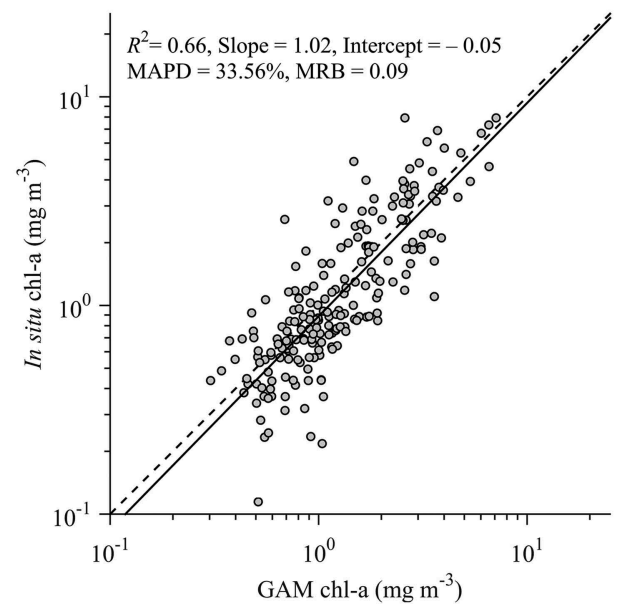

Figure 2. Statistical comparisons of in situ measured chl-a and satellite-derived chl-a for (a) OC3M algorithm and (b) GAM algorithm. Dotted line and dashed lines represent the 1:1 line and the linear regression fit on log-transformed data, respectively. The corresponding statistical indicators are given in each panel.

overestimation in OC3M chl-a estimates. The poor correlation $\left(R^{2}=0.21\right)$ and high deviation of the regression line from 1:1 line (slope $=0.55$ ) also indicate that the OC3M chl-a algorithm has profound systematic errors when applied to the BYS (Figure 2(a)). In contrast, the GAM chl-a algorithm was characterized by much lower uncertainty $\left(M A P D=33.56 \%, M R D=0.09 \mathrm{mg} \mathrm{m}^{-3}\right.$ ) and minimal deviation from the 1:1 relationship (slope $\left.=1.02, R^{2}=0.66\right)$ (Figure 2(b)).

\subsection{Spatial comparisons for each cruise}

For spatial comparison between the satellite-derived and in situ measured chl-a, the in situ measured chl-a plots, and the corresponding satellite chl-a composites for each cruise are shown and compared in Figure 3. Figure 3(a) shows the spatial distributions of in situ measured chl-a (the colour of scatter indicates chl-a concentration). The satellite chl-a maps were derived using the OC3M (Figure 3(b)) and GAM (Figure 3(c)) algorithms, respectively. In spring 2010 and spring 2014, both OC3M and GAM maps displayed obvious chl-a blooms in offshore waters as indicated by the in situ observation. In late spring 2012, the OC3M map presents some high chl-a patches over the Bohai Sea and northern Yellow Sea, while this feature was not shown in the GAM and in situ maps. During summer 2013 and late summer 2015, both the OC3M and GAM maps showed consistent spatial patterns, with chl-a increasing from deep to shallow waters, and this is also displayed on the in situ maps. During late autumn 2012, 2013, 2014, and winter 2016, the GAM and in situ chl-a maps were spatially homogenous, whereas the OC3M maps were characterized by a high chl-a gradient between the offshore and coastal waters. Overall, the results indicate that the chl-a patterns produced by GAM algorithm had closer correspondence with the in situ chl-a distribution than the standard OC3M 

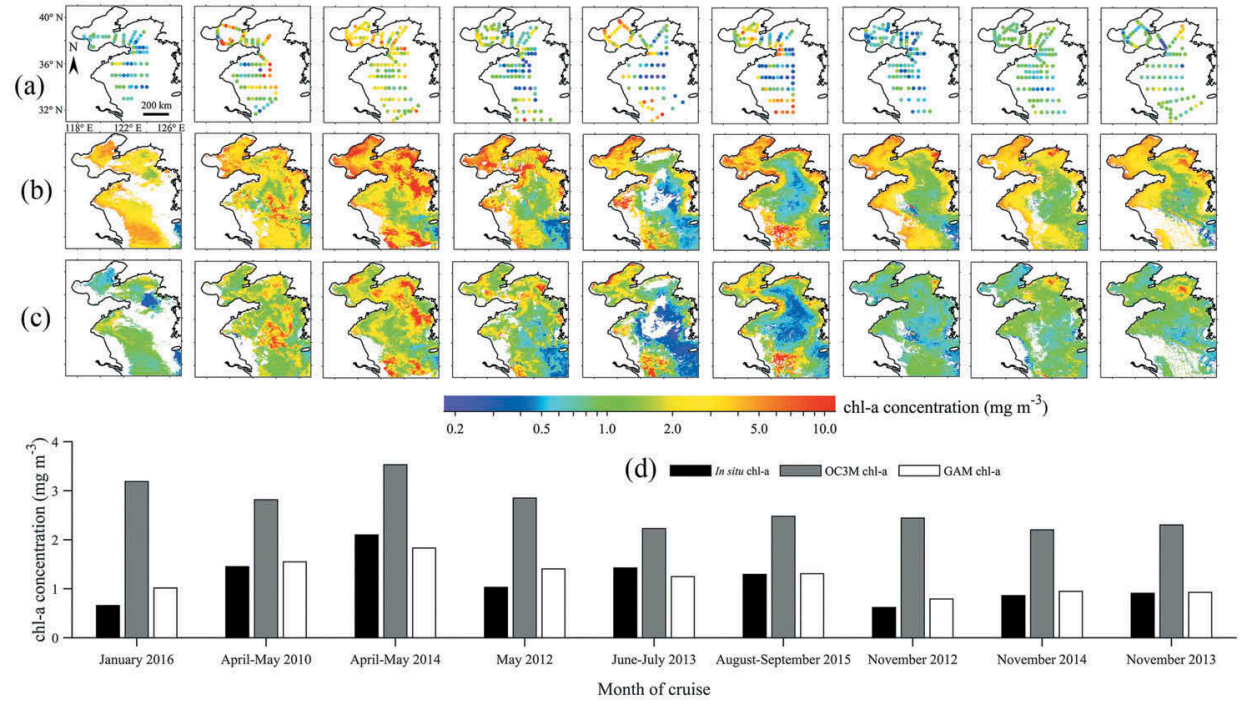

Figure 3. Spatial distributions of (a) in situ chl-a measurements, (b) OC3M satellite chl-a and (c) GAM satellite chl-a composites for each of the nine cruises (from left to right in order: January 2016, AprilMay 2010, April-May 2014, May 2012, June-July 2013, August-September 2015, November 2012, November 2014 and November 2013, respectively), and (d) the series of chl-a averages during the period of each cruise.The text on the top of images indicates the time for each column images. Notice that each of the (a)-(c) maps and the (d) data series was arranged according to monthly climatology in order to better represent their seasonal variations.

algorithm. In particular, the highly erroneous chl-a overestimation over coastal waters and during the cold seasons (autumn and winter) displayed in the OC $3 \mathrm{M}$ chl-a maps was largely and obviously corrected in the GAM chl-a maps. The averages of each map in Figure $3(\mathrm{a}-\mathrm{c})$ were plotted and compared as a series in Figure 3(d). The overestimation of OC3M chl-a was further confirmed by this analysis, while the GAM chl-a was in good agreement with the in situ chl-a (Figure 3(d)). From the view of temporal variations, OC3M chl-a series was not correlated with the in situ chl-a (Spearman rank correlation, $r$ $=0.30, p=0.44, N=9$ ), whereas the GAM chl-a series presents a nearly consistent temporal variation with the in situ chl-a (Spearman rank correlation, $r=0.87, p$ $<0.01, N=9$ ).

\subsection{Time-series comparisons}

Figure 4 presents the time series of satellite chl-a monthly averages from January 2010 to March 2016 for both OC3M and GAM in the target regions overlain with the in situ chl-a averages. To quantify the correlation between satellite and in situ chl-a series, the sampled satellite chl-a series for each region were extracted from both OC3M and GAM chl-a series according to the date span of each of the cruises. The Spearman rank correlation analyses between sampled satellite chl-a and in situ measured chl-a are given in Table 1.

For the chl-a series of the entire BYS (Figure 4(a)), the OC3M produced obviously higher chl-a $\left(1.18 \mathrm{mg} \mathrm{m}^{3}-3.36 \mathrm{mg} \mathrm{m}^{3}\right)$ than GAM $\left(0.57 \mathrm{mg} \mathrm{m}^{3}-1.88 \mathrm{mg} \mathrm{m}^{3}\right)$ and in situ 
(a)

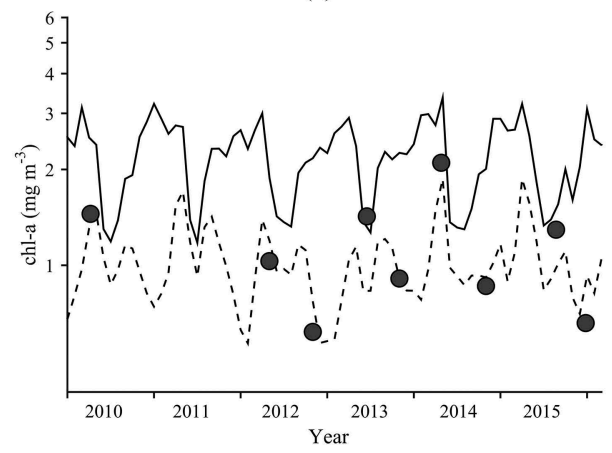

(c)

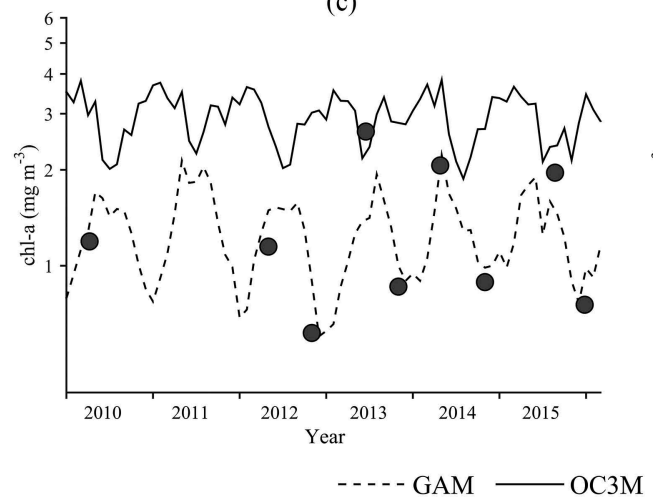

(b)

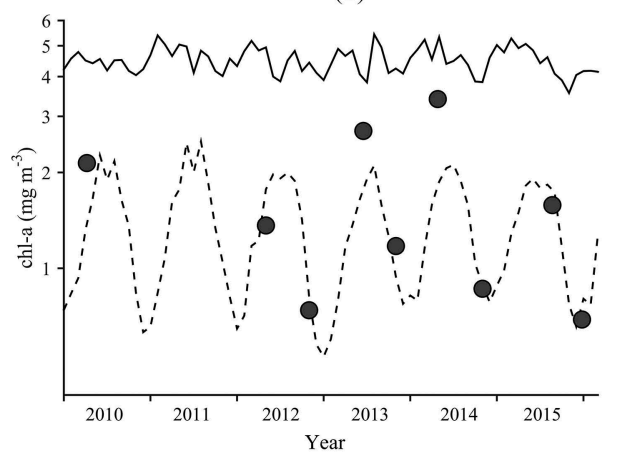

(d)

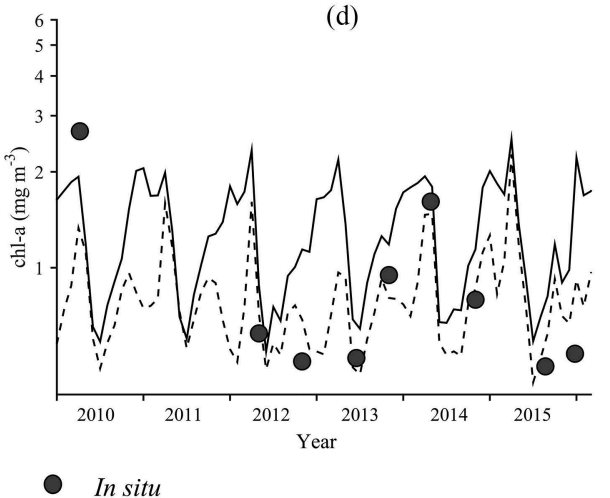

Figure 4. The time series of monthly chl-a averages generated from satellite products for (a) the entire BYS region, (b) coastal region, (c) transition region, and (d) deep region. The solid line is the OC3M chl-a, the dotted line is GAM chl-a, and filled circle is in situ chl-a averages for each cruise.

Table 1. Results of the Spearman rank correlation analyses between satellite-derived and in situ measured chl-a over different regions. The correlation coefficient and significance level are given by $r$ and $p$, respectively. The significant $r$ values are highlighted in bold.

\begin{tabular}{lcccccccc}
\hline Model & \multicolumn{2}{c}{ Entire region } & \multicolumn{2}{c}{ Depth $(\mathrm{m})<20$} & \multicolumn{2}{c}{$20 \leq$ Depth $(\mathrm{m})<50$} & \multicolumn{2}{c}{ Depth $(\mathrm{m}) \leq 50$} \\
\hline & $r$ & $p$ & $r$ & $p$ & $r$ & $p$ & $r$ & $p$ \\
OC3M versus in situ & 0.30 & 0.44 & -0.07 & 0.88 & -0.10 & 0.81 & 0.50 & 0.18 \\
GAM versus in situ & $\mathbf{0 . 8 7}$ & $<0.01$ & $\mathbf{0 . 7 2}$ & $<0.05$ & $\mathbf{0 . 8 5}$ & $<0.01$ & $\mathbf{0 . 8 7}$ & $<0.01$ \\
\hline
\end{tabular}

measurements $\left(0.62 \mathrm{mg} \mathrm{m}^{3}-2.10 \mathrm{mg} \mathrm{m}^{3}\right)$. The OC3M chl-a series have high values from November to April and low values from June to September (Figure 4(a)), which is conflict with the low values of in situ chl-a in January 2016, November 2012, November 2013 and November 2014 (Figure 4(a)). However, the GAM chl-a series produced two peaks from April to May and from September to October with the lowest values from November to February, which was closer to the in situ observations.

In the coastal region (Figure 4(b)), OC3M gave consistently higher chl-a values (3.55 $\mathrm{mg} \mathrm{m}^{3}-5.53 \mathrm{mg} \mathrm{m}^{3}$ ) than in situ $\left(0.69 \mathrm{mg} \mathrm{m}^{3}-3.40 \mathrm{mg} \mathrm{m}^{3}\right)$ and GAM $(0.53 \mathrm{mg}$ $\mathrm{m}^{3}-2.50 \mathrm{mg} \mathrm{m}^{3}$ ). Most of the in situ observations were close to the GAM chl-a series, except for two samples; in summer 2013 and spring 2014 (Figure 4(b)) which might be the result of underestimation of the chl-a values during phytoplankton blooms. The 
OC3M chl-a series has no regular seasonal cycle, while GAM chl-a presents one peak from spring to summer and the lowest value in winter which is consistent with the temporal variability of in situ chl-a (Figure 4(b)).

In the transition region (Figure $4(\mathrm{c}))$, the OC3M still produced higher chl-a $(1.88 \mathrm{mg}$ $\left.\mathrm{m}^{3}-3.83 \mathrm{mg} \mathrm{m}^{3}\right)$ than GAM $\left(0.60 \mathrm{mg} \mathrm{m}^{3}-2.23 \mathrm{mg} \mathrm{m}^{3}\right)$ and in situ measurements $(0.61 \mathrm{mg}$ $\mathrm{m}^{3}-2.64 \mathrm{mg} \mathrm{m}^{3}$ ). There are notable discrepancies in seasonal cycles between OC3M chla and GAM chl-a (Figure 4(c)). The OC3M chl-a series have high values from autumn to winter and low values in summer, which is nearly opposite to the in situ chl-a variations. The GAM and in situ chl-a had similar temporal patterns, with high values persisting from spring to autumn and the lowest values being observed in winter (Figure 4(c)).

In the offshore region (Figure $4(\mathrm{~d})$ ), the magnitude of OC3M chl-a $\left(0.55 \mathrm{mg} \mathrm{m}^{3}-2.54 \mathrm{mg} \mathrm{m}^{3}\right)$ was similar to in situ chl-a $\left(0.49 \mathrm{mg} \mathrm{m}^{3}-2.68 \mathrm{mg} \mathrm{m}^{3}\right)$ as well as the GAM chl-a $\left(0.44 \mathrm{mg} \mathrm{m}^{3}-\right.$ $2.27 \mathrm{mg} \mathrm{m}^{3}$ ). The seasonal cycle of OC3M chl-a was characterized by a long-lasting high values from autumn to the following spring and one trough in summer, while the GAM chl-a presents a bimodal seasonal cycle with a distinct spring peak and a weak autumn peak as well as low values in winter and summer (Figure 4(d)). Compared to GAM chl-a, the low values of in situ chl-a in November 2014 and January 2016 were not well exhibited in the OC3M chl-a series (Figure 4(d)).

Table 1 indicates that there is no significant correlation between OC3M chl-a and in situ chl-a in any region, while the GAM chl-a has significant correlations with in situ chl-a in all regions. The results further confirmed that the OC3M is not only inaccurate for quantifying the magnitude of chl-a, but also performed poorly in representing temporal patterns. In contrast, the GAM chl-a algorithm performed well both on both magnitude and temporal patterns of chl-a in comparisons with in situ measurements.

\subsection{Seasonal cycles of chl-a in different regions}

To gain a new insight into seasonal cycles of chl-a over the BYS, the pentad climatological series of satellite chl-a averages and the corresponding in situ chl-a averages over each target region for the corresponding calendar date are plotted in Figure 5 . As shown in the previous section, the seasonal patterns of satellite chl-a derived using OC3M and GAM algorithm are clearly differentiated over each of the three depth regions. Compared with OC $3 \mathrm{M}$ chl-a, the GAM chl-a presents a seasonal cycle much more consistent with in situ chl-a. Consequently, the seasonal cycle of chl-a was examined in further detail using the GAM chl-a data series. As a temperate ocean, the seasonal cycle of mean chl-a over the entire BYS was characterized by a typical bimodal pattern (Thomas, Townsend, and Weatherbee 2003; Ueyama and Monger 2005), with two chl-a peaks in spring and autumn and two troughs in summer and winter, respectively (Figure 5(a)). In the coastal region, a long-lasting high chl-a period was observed from May to October, and following this, a minimum during winter (Figure 5(b)). In the offshore region, the chl-a time series were characterized by a distinct spring peak associated with a weak autumn peak, and the minima were observed in summer and winter (Figure 5(d)). In the transition region, a long-lasting high chl-a period occurred from spring to autumn with a minor summertime dip and the minimum in winter. This seasonal pattern of chl-a appears to be an intermediate regime between the coastal and offshore regions (Figure 5(c)). 
(a)

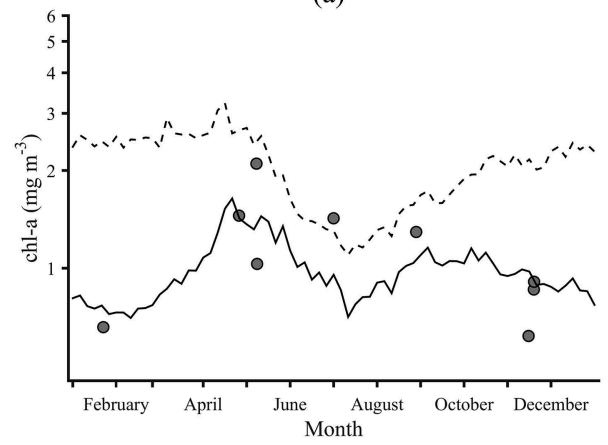

(c)

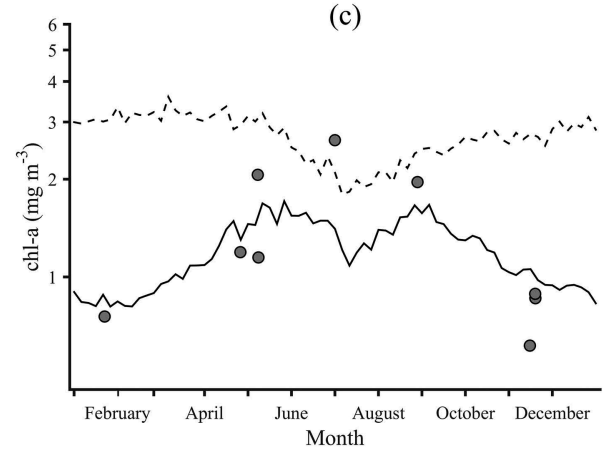

(b)

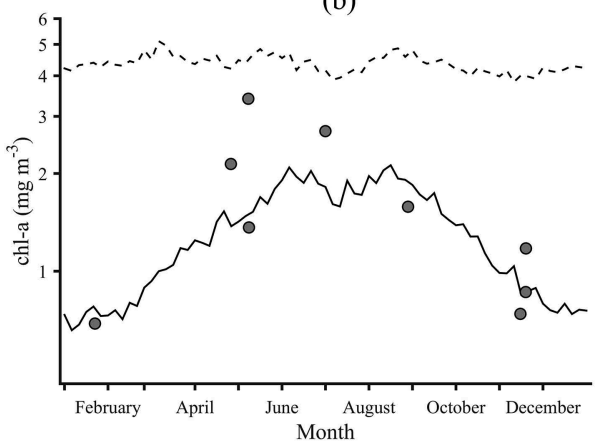

(d)

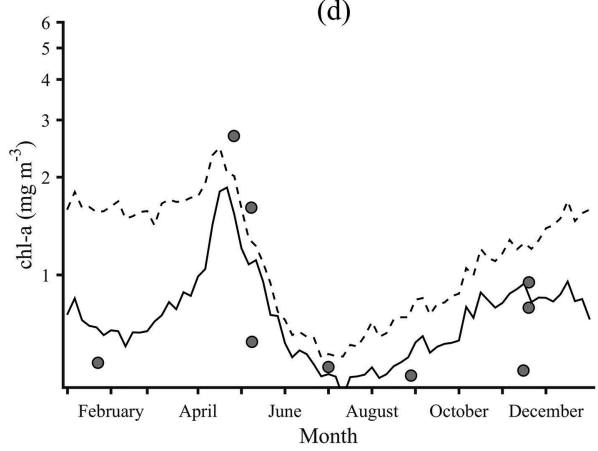

Figure 5. Pentad climatological time series of satellite chl-a averages for the (a) entire BYS, (b) the coastal region, (c) the transitional region, and (d) the deep region, respectively. The circles represent in situ chl-a averages over the corresponding region according to their calendar date.

\section{Discussion}

\subsection{Reliability of seasonal patterns from satellite chl-a products}

The comparisons between satellite-derived and in situ measured chl-a enabled a conclusion that the standard OC $3 \mathrm{M}$ chl-a has large errors in both magnitude and temporal patterns when applied to the BYS. This overestimation of OC3M chl-a has been reported previously (Shang et al. 2014; Yamaguchi et al. 2012; Cui et al. 2014) but has not been so clearly quantified as in the present study. However, previous studies regarded the use of OC $3 \mathrm{M}$ chl-a as being accurate when applied only to consideration of relative patterns of temporal variability in the BYS (Zhang et al. 2017; Wu et al. 2016; Chen and Liu 2015; Liu and Wang 2013). The results of the present study show the conclusions from these earlier studies should be treated with caution, because of a clear discrepancy in seasonal patterns derived by OC3M when compared with in situ chl-a. The degree of overestimation in OC3M chl-a varied in time and space, which clearly distorted chl-a seasonality when compared with in situ chl-a. The seasonal patterns of chl-a averages were found to be significantly different between OC3M and in situ chl-a over all subregions, especially for the coastal region. From the time-series comparisons, we can deduce that the divergence of seasonal cycles between OC3M and in situ chl-a mainly results from the more severe overestimation of OC $3 \mathrm{M}$ chl-a values during winter months. Generally, the severely overestimated chl-a values are the results of large errors 
in atmospheric correction and/or improper chl-a retrieval models, which are related to high suspended sediments and/or colour dissolved organic matter (CDOM) due to the strong wind-induced mixing in winter (Son, Wang, and Shon 2011; Yamaguchi et al. 2013; Son et al. 2014).

In addition, the GAM chl-a algorithm reported in our previous paper (Wang, Liu, and Tang 2017) was also assessed using the in situ chl-a measurements, as a comparison with the standard OC3M chl-a algorithm. Compared with OC3M chl-a, the GAM chl-a performed better, corresponding well with the in situ chl-a values, both in absolute value and for the seasonal patterns. The reasons for this improvement were discussed in Wang, Liu, and Tang (2017) but relate primarily to the use of more optical bands, more regionally appropriate atmospheric correction, and accommodating the effect of suspended sediment on chl-a estimation in turbid coastal waters.

Besides the GAM chl-a algorithm, there are other chl-a algorithms that can be applied in the BYS, such as the Tassan-like chl-a algorithm (Siswanto et al. 2011) which was not evaluated in this study. The chl-a maps produced by the Tassan-like algorithm (Yamaguchi et al. 2013; Zhang et al. 2017) and the GAM algorithm have similar characteristics as both alleviate the overestimation of chl-a values over high suspended sediment waters. The GAM algorithm validated here against an extensive set of in situ chl-a measurements collected over a 7-year period outperformed the standard OC3M algorithm producing reliable derived values of chl-a in both magnitude and seasonality over the BYS.

\subsection{Mechanisms underlying seasonal patterns of chl-a}

The improved chl-a product derived by GAM algorithm provided a new insight into the seasonal cycles of sea surface chl-a over the BYS. The GAM chl-a climatology reveals three distinct seasonal patterns: a coastal component, with a single chl-a peak in the boreal summer; an oceanic component, with a typical bimodal pattern (with a strong spring peak and a weaker autumn peak); and a transitional component separating these two regimes, with high chl-a levels from spring to autumn with a small summertime dip. As a temperate continental shelf marine ecosystem, the chl-a dynamics of the BYS reflects a tight balance between nutrient supply and light availability (Walsh 1988; Smetacek 1991).

In the coastal region, the long-lasting summer chl-a peak coincides well with the emergent summer monsoon over eastern China (Qian, Kang, and Lee 2002). On the one hand, the summer monsoon brings a large quantity of rain to the BYS surrounds, and thus increases loadings of the terrestrial nutrients via increasing run-off from the land into the sea (Qian, Kang, and Lee 2002). As a result, the trophic level in coastal waters increases significantly in summer. On the other hand, the wind-induced vertical mixing of the water column is weak in summer due to weak sea surface winds. This weak vertical mixing leads to low turbidity of the water (Bian et al. 2013), increasing light availability in the surface water. Consequently, the high trophic level combined with favourable light conditions can significantly accelerate phytoplankton growth and cause a long-lasting summer chl-a peak in the coastal region of the BYS. In winter, the low chla values are mainly attributed to the light limitation in surface waters resulting from high turbidity, caused by strong winds (Bian et al. 2013).

In the offshore region, a strong spring bloom develops as light availability increases in the spring and nutrients are sufficient at the surface due to strong wintertime mixing 
(Hyun and Kim 2003). In addition, the Yellow Sea Warm Current might bring some nutrients into the central Yellow Sea from the subsurface nutrient-rich water of the Kuroshio and/or from the Changjiang (Yangtze) River estuary (Liu et al. 2015).This bloom generally persists for a few weeks to months until the nutrients are depleted and zooplankton grazing terminates the bloom. The phytoplankton bloom disappears in summer as strong sea surface stratification occurs due to high sea surface temperature, weak sea surface wind, and the strong Yellow Sea Cold Water Mass (Zhang et al. 2008). The strong sea surface stratification reduces nutrient supplementation from the deeper layer and thus limits the growth of phytoplankton (Hyun and Kim 2003; Naimie, Blain, and Lynch 2001). Then, a secondary weak phytoplankton bloom occurs in fall as nutrient limitation is released by surface cooling and thus convective mixing (Naimie, Blain, and Lynch 2001; Wang, Wang, and Zhan 2003). From autumn to winter, the vertical mixing is gradually intensified by the increasing sea surface wind stress, and turbidity of the water is enhanced due to the resuspension of bottom sediment (Bian et al. 2013). Therefore, the light availability is gradually reduced during this period. Although there are plenty of nutrients accumulated in surface water, the light limitation restricts phytoplankton growth in winter, resulting in a secondary trough of sea surface chl-a values.

In the transition region, the mechanisms for regulating chl-a dynamics are complicated reflecting an intermediate condition between shallow coastal and deeper offshore regions. During winter, the phytoplankton growth is under light limitation due to high water turbidity resulting from wind-induced, strong sediment resuspension. When the wind weakens in spring, the phytoplankton grows rapidly using nutrients accumulated in wintertime and from a deepening euphotic layer, a prominent spring bloom occurs. In summer, a small dip in chl-a occurs following the vertical stratification of the water column. Because some nutrients might be supplied from horizontal transmission between coastal waters and transition waters (Liu and Wang 2013), the chl-a value is not very depressed in summer. From summer to autumn, the phytoplankton grows rapidly again with increasing nutrients supplemented from the deep layer due to the disappearance of water stratification. Theoretically, the nutrients supplemented from the deep layer starts earlier in the shallow area than in the deep area; thus the occurrence of an autumn phytoplankton bloom in the transition region occurs 1-2 months earlier than that of the deep region.

\subsection{Uncertainties in chl-a estimates}

Due to the limited number of in situ chl-a measurements, some compromises had to be applied in the evaluation process. Therefore, we must acknowledge that some uncertainties and limitations still exist in evaluating the results of this study.

First, uncertainties might result from the relaxed match-up criterion in the statistical comparisons between satellite and in situ chl-a. Strictly, the standard match-up criterion was common as follows (Bailey and Werdell 2006; Wang, Son, and Shi 2009): (1) a time window of $\pm 3 \mathrm{~h}$ was set to acquire matching pairs; (2) the number of valid pixels in the defined window was no less than 13; and (3) the value of each pixel in the defined $5 \times 5$ box must be between (mean value $+1.5 \times$ standard deviation) and (mean value $1.5 \times$ standard deviation). In this study, the time window was relaxed to $\pm 24 \mathrm{~h}$, in order to acquire sufficient match-ups and to compare in situ measurements with the results of 
the GAM chl-a algorithm reported in Wang, Liu, and Tang (2017). However, the time window $( \pm 24 \mathrm{~h}$ ) for match-up generation may be too large given the significant terrestrial and tidal influences in the BYS, and because natural variations in ocean properties are likely to occur over shorter time spans. For example, the hourly ocean colour products from the Korean Geostationary Ocean Color Imager (GOCI) demonstrated significant diurnal variations in ocean optical, biological, and biogeochemical properties in the Bohai Sea, Yellow Sea, and East China Sea (Wang et al. 2013). Hence, a strict spatial-temporal match-up scheme (commonly less than $3 \mathrm{~h}$ ) may be recommended for turbid coastal areas (Cui et al. 2010). In the future, further chl-a in situ observations will permit stricter (shorter time window) match-up analyses.

Second, for the comparison of patterns between satellite and in situ chl-a in subsection 3.2 and subsection 3.3, the in situ chl-a maps were directly compared with composite satellite chl-a maps for each cruise. In fact, the times of in situ observations were quite different from the time spans of satellite scan. In the map of in situ chl-a, the sampling times were different from each other, whereas the monitored time of all pixels in the satellite map was nearly identical. The results shown in the in situ maps represent successive values measured during the cruise, while the results shown in the satellite maps are the averages during the period of each cruise.

Third, the standard MODIS $R_{\mathrm{rs}}$ which were produced by standard near-infrared (NIR) based atmospheric correction were used for satellite chl-a estimation using OC3M and GAM algorithms. The standard NIR-based atmospheric correction is basically assumed to be black at two NIR bands (748 $\mathrm{nm}$ and $869 \mathrm{~nm}$ ) for the open waters (Gordon and Wang 1994), but this NIR black assumption may be invalid for coastal waters due to the obvious backscattering and absorption of CDOM and non-algal particles (Siegel et al. 2000). As typical turbid water, the failure of NIR-based atmospheric correction could lead to significant errors in MODIS standard $R_{\mathrm{rs}}$ data in BYS (Wang and Shi 2007). For example, the MODIS $R_{\mathrm{rs}}$ at visible bands presents significant biases with a median of APD (absolute percentage of difference) of $18 \%-28 \%$ along the Yellow Sea coast (Cui et al. 2014). These uncertainties in satellite $R_{\mathrm{rs}}$ may propagate into the OC3M and GAM chl-a estimations in our study. To improve the $R_{\mathrm{rs}}$ accuracy, the atmospheric correction approaches based on NIR similarity spectrum algorithm, NIR-SWIR (short-wave infrared) algorithm, and artificial neural network algorithm (Goyens, Jamet, and Schroeder 2013) could be tried in future studies.

\section{Conclusion}

The accuracy of the standard OC3M satellite chl-a algorithm was evaluated using extensive in situ chl-a measurements over the BYS. The extent of overestimation of chl-a values by the standard OC3M algorithm values was quantified, and the extent of distortion of chl-a seasonality was shown to be significant. The large overestimation of OC3M chl-a in winter was primarily responsible for the deviation from seasonal patterns shown by in situ chl-a. Therefore, conclusions made in studies based on OC3M chl-a magnitudes and seasonality in the BYS should be treated with caution. The result of this study opposes the use of the standard OC3M algorithm in the BYS. Compared with the OC3M algorithm, a previously reported regional GAM chl-a algorithm for the BYS produced more accurate derived chl-a values and a seasonality consistent with the in situ measurements, making it a more suitable chl-a algorithm for use in the BYS. 


\section{Acknowledgments}

The authors would like to thank the Ocean Biology Processing Group of NASA for providing the MODIS data set (http://oceancolor.gsfc.nasa.gov/).

\section{Disclosure statement}

No potential conflict of interest was reported by the authors.

\section{Funding}

This work was supported by the National Natural Science Foundation of China [41706134, 41876107]; the Aoshan Science and Technology Innovation Program of Qingdao National Laboratory for Marine Science and Technology [2016ASKJ02]; the Strategic Priority Research Program of the Chinese Academy of Sciences [XDA11020702]; and the Basic Special Program of Ministry of Science and Technology [2014FY210600].

\section{References}

Bailey, S. W., and P. Jeremy Werdell. 2006. "A Multi-Sensor Approach for the On-Orbit Validation of Ocean Color Satellite Data Products." Remote Sensing of Environment 102 (1-2): 12-23. doi:10.1016/j.rse.2006.01.015.

Bian, C., W. Jiang, Q. Quan, T. Wang, R. J. Greatbatch, and W. Li. 2013. “Distributions of Suspended Sediment Concentration in the Yellow Sea and the East China Sea Based on Field Surveys during the Four Seasons of 2011." Journal of Marine Systems 121-122: 24-35. doi:10.1016/j. jmarsys.2013.03.013.

Campbell, J. W. 1995. "The Lognormal Distribution as a Model for Bio-Optical Variability in the Sea." Journal of Geophysical Research 100 (C7): 13237-13254. doi:10.1029/95jc00458.

Chen, J., and J. Liu. 2015. "The Spatial and Temporal Changes of Chlorophyll-A and Suspended Matter in the Eastern Coastal Zones of China during 1997-2013." Continental Shelf Research 95: 89-98. doi:10.1016/j.csr.2015.01.004.

Chen, J., and W. Quan. 2013. "An Improved Algorithm for Retrieving Chlorophyll-A from the Yellow River Estuary Using MODIS Imagery." Environmental Monitoring and Assessment 185 (3): 2243-2255. doi:10.1007/s10661-012-2705-y.

Cui, T., J. Zhang, J. Tang, S. Sathyendranath, S. Groom, Y. Ma, W. Zhao, and Q. Song. 2014. "Assessment of Satellite Ocean Color Products of MERIS, MODIS and SeaWiFS along the East China Coast (In the Yellow Sea and East China Sea)." ISPRS Journal of Photogrammetry and Remote Sensing 87: 137-151. doi:10.1016/j.isprsjprs.2013.10.013.

Cui, T., J. Zhang, S. Groom, L. Sun, T. Smyth, and S. Sathyendranath. 2010. "Validation of MERIS Ocean-Color Products in the Bohai Sea: A Case Study for Turbid Coastal Waters." Remote Sensing of Environment 114 (10): 2326-2336. doi:10.1016/j.rse.2010.05.009.

$\mathrm{Fu}, \mathrm{Y} ., \mathrm{S} . \mathrm{Xu}$, and J. Liu. 2016. "Temporal-Spatial Variations and Developing Trends of Chlorophyll-A in the Bahai Sea, China." Estuarine, Coastal and Shelf Science 173: 49-56. doi:10.1016/j.ecss.2016.02.016.

Gordon, H. R. 1997. "Atmospheric Correction of Ocean Color Imagery in the Earth Observing System Era." Chlorophyll a Algorithms for Oligotrophic Oceans 102 (D14): 17081-17106. doi:10.1029/96jd02443.

Gordon, H. R., and M. Wang. 1994. "Retrieval of Water-Leaving Radiance and Aerosol Optical Thickness over the Oceans with SeaWiFS: A Preliminary Algorithm." Applied Optics 33 (3): 443-452. doi:10.1364/ao.33.000443. 
Goyens, C., C. Jamet, and T. Schroeder. 2013. "Evaluation of Four Atmospheric Correction Algorithms for MODIS-Aqua Images over Contrasted Coastal Waters." Remote Sensing of Environment 131: 63-75. doi:10.1016/j.rse.2012.12.006.

Gregg, W. W., M. E. Conkright, P. Ginoux, J. E. O'Reilly, and N. W. Casey. 2003. "Ocean Primary Production and Climate: Global Decadal Changes." Geophysical Research Letters 30 (15): 1809. doi:10.1029/2003gl016889.

Hyun, J.-H., and K.-H. Kim. 2003. "Bacterial Abundance and Production during the Unique Spring Phytoplankton Bloom in the Central Yellow Sea." Marine Ecology Progress Series 252: 77-88. doi:10.3354/meps252077.

IOCCG. 2000. "Remote Sensing of Ocean Colour in Coastal and Other Optically Complex Waters, Reports of the International Ocean-Colour Coordination Group, No. 3." In Reports of the International Ocean Color Coordinating Group, edited by S. Sathyendranath, 140. Canada: Dartmouth.

Liu, D., and Y. Wang. 2013. "Trends of Satellite Derived Chlorophyll-A (1997-2011) in the Bohai and Yellow Seas, China: Effects of Bathymetry on Seasonal and Inter-Annual Patterns." Progress in Oceanography 116: 154-166. doi:10.1016/j.pocean.2013.07.003.

Liu, X., B. Huang, Q. Huang, L. Wang, N. Xiaobo, Q. Tang, S. Sun, et al. 2015. "Seasonal Phytoplankton Response to Physical Processes in the Southern Yellow Sea." Journal of Sea Research 95: 45-55. doi:10.1016/j.seares.2014.10.017.

Lorenzen, C. J. 1967. "Determination of Chlorophyll and Pheopigments: Spectrophotometric Equations." Limnology and Oceanography 12 (2): 343-346. doi:10.4319/lo.1967.12.2.0343.

Melin, F., G. Zibordi, and J. F. Berthon. 2007. "Assessment of Satellite Ocean Color Products at a Coastal Site." Remote Sensing of Environment 110 (2): 192-215. doi:10.1016/j.rse.2007.02.026.

Naimie, C., C. A. Blain, and D. R. Lynch. 2001. "Seasonal Mean Circulation in the Yellow Sea A Model-Generated Climatology." Continental Shelf Research 21 (6-7): 667-695. doi:10.1016/ S0278-4343(00)00102-3.

NASA Oceancolor level 2 sea surface remote sensing reflectance products. Accessed February 14 2017. http://oceancolor.gsfc.nasa.gov/cms/

O'Reilly, J. E., S. Maritorena, and D. Siegel. 2000. "Ocean Color Chlorophyll a Algorithms for SeaWiFS, OC2, and OC4: Version 4." In SeaWiFS Postlaunch Calibration and Validation Analyses Part 3, edited by S.B. Hooker and E.R. Firestone, 9-23. NASA Goddard Space Flight Center.

Odermatt, D., A. Gitelson, V. E. Brando, and M. Schaepman. 2012. "Review of Constituent Retrieval in Optically Deep and Complex Waters from Satellite Imagery." Remote Sensing of Environment 118: 116-126. doi:10.1016/j.rse.2011.11.013.

Qian, W., H. S. Kang, and D. K. Lee. 2002. “Distribution of Seasonal Rainfall in the East Asian Monsoon Region." Theoretical and Applied Climatology 73 (3-4): 151-168. doi:10.1007/s00704-002-0679-3.

Richards, F. A., and T. G. Thompson. 1952. "The Estimation and Characterization of Plankton Populations by Pigment Analyses. 2. A Spectrophotometric Method for the Estimation of Plankton Pigments." Journal of Marine Research 11 (2): 156-172.

Ryther, J. H., and C. S. Yentsch. 1957. "The Estimation of Phytoplankton Production in the Ocean from Chlorophyll and Light Data." Limnology and Oceanography 2 (3): 281-286. doi:10.1002/ Ino.1957.2.3.0281.

Shang, S. L., Q. Dong, C. M. Hu, G. Lin, Y. H. Li, and S. P. Shang. 2014. "On the Consistency of MODIS Chlorophyll a Products in the Northern South China Sea." Biogeosciences 11 (2): 269-280. doi:10.5194/bg-11-269-2014.

Shi, W., and M. H. Wang. 2012. "Satellite Views of the Bohai Sea, Yellow Sea, and East China Sea." Progress in Oceanography 104: 30-45. doi:10.1016/j.pocean.2012.05.001.

Shi, W. S., and M. H. Wang. 2010. "Satellite Observations of the Seasonal Sediment Plume in Central East China Sea." Journal of Marine Systems 82 (4): 280-285. doi:10.1016/j.jmarsys.2010.06.002.

Siegel, D. A., M. Wang, S. Maritorena, and W. Robinson. 2000. "Atmospheric Correction of Satellite Ocean Color Imagery: The Black Pixel Assumption." Applied Optics 39 (21): 3582-3591. doi:10.1364/ao.39.003582.

Siegel, D. A., M. J. Behrenfeld, S. Maritorena, C. R. McClain, D. Antoine, S. W. Bailey, P. S. Bontempi, et al. 2013. "Regional to Global Assessments of Phytoplankton Dynamics from the SeaWiFS Mission." Remote Sensing of Environment 135: 77-91. doi:10.1016/j.rse.2013.03.025. 
Siswanto, E., J. Tang, H. Yamaguchi, Y.-H. Ahn, J. Ishizaka, S. Yoo, S.-W. Kim, et al. 2011. "Empirical Ocean-Color Algorithms to Retrieve Chlorophyll-A, Total Suspended Matter, and Colored Dissolved Organic Matter Absorption Coefficient in the Yellow and East China Seas." Journal of Oceanography 67 (5): 627-650. doi:10.1007/s10872-011-0062-z.

Smetacek, V. 1991. "Coastal Eutrophication: Causes and Consequences." In Ocean Margin Processes in Global Change, edited by R. Mantoura, J. M. Martin and R. Wollast, 251-280. Chichester: John Wiley.

Son, S. H., M. Wang, and J.-K. Shon. 2011. "Satellite Observations of Optical and Biological Properties in the Korean Dump Site of the Yellow Sea." Remote Sensing of Environment 115 (2): 562-572. doi:10.1016/j.rse.2010.10.002.

Son, S. H., Y. H. Kim, J. Kwon, H.-C. Kim, and K.-S. Park. 2014. "Characterization of Spatial and Temporal Variation of Suspended Sediments in the Yellow and East China Seas Using Satellite Ocean Color Data." GIScience \& Remote Sensing 51 (2): 212-226. doi:10.1080/ 15481603.2014.895580.

Thomas, A. C., D. W. Townsend, and R. Weatherbee. 2003. "Satellite-Measured Phytoplankton Variability in the Gulf of Maine." Continental Shelf Research 23 (10): 971-989. doi:10.1016/ S0278-4343(03)00086-4.

Ueyama, R., and B. C. Monger. 2005. "Wind-Induced Modulation of Seasonal Phytoplankton Blooms in the North Atlantic Derived from Satellite Observations." Limnology and Oceanography 50 (6): 1820-1829. doi:10.4319/lo.2005.50.6.1820.

Walsh, J. J. 1988. On The Nature Of Continental Shelves. New York: Academic press.

Wang, B., X. Wang, and R. Zhan. 2003. "Nutrient Conditions in the Yellow Sea and the East China Sea." Estuarine, Coastal and Shelf Science 58 (1): 127-136. doi:10.1016/s0272-7714(03)00067-2.

Wang, M., J. Tang, and W. Shi. 2007. "MODIS-derived Ocean Color Products along the China East Coastal Region." Geophysical Research Letters 34 (6): L06611. doi:10.1029/2006gl028599.

Wang, M., J.-H. Ahn, L. Jiang, W. Shi, S. H. Son, Y.-J. Park, and J.-H. Ryu. 2013. “Ocean Color Products from the Korean Geostationary Ocean Color Imager (GOCI)." Optics Express 21 (3): 3835-3849. doi:10.1364/OE.21.003835.

Wang, M., S. H. Son, and W. Shi. 2009. "Evaluation of MODIS SWIR and NIR-SWIR Atmospheric Correction Algorithms Using SeaBASS Data." Remote Sensing of Environment 113 (3): 635-644. doi:10.1016/j.rse.2008.11.005.

Wang, M., and W. Shi. 2007. "The NIR-SWIR Combined Atmospheric Correction Approach for MODIS Ocean Color Data Processing." Optics Express 15 (24): 15722-15733.

Wang, Y. Q., D. Y. Liu, and D. L. Tang. 2017. "Application of a Generalized Additive Model (GAM) for Estimating Chlorophyll-A Concentration from MODIS Data in the Bohai and Yellow Seas, China." International Journal of Remote Sensing 38 (3): 639-661. doi:10.1080/ 01431161.2016 .1268733$.

Wu, X., H. Duan, N. Bi, P. Yuan, A. Wang, and H. Wang. 2016. "Interannual and Seasonal Variation of Chlorophyll-A off the Yellow River Mouth (1997-2012): Dominance of River Inputs and Coastal Dynamics." Estuarine, Coastal and Shelf Science 183: 402-412. doi:10.1016/j.ecss.2016.08.038.

Yamaguchi, H., H.-C. Kim, Y. B. Son, S. W. Kim, K. Okamura, Y. Kiyomoto, and J. Ishizaka. 2012. "Seasonal and Summer Interannual Variations of SeaWiFS Chlorophyll a in the Yellow Sea and East China Sea." Progress in Oceanography 105: 22-29. doi:10.1016/j.pocean.2012.04.004.

Yamaguchi, H., J. Ishizaka, E. Siswanto, Y. B. Son, S. Yoo, and Y. Kiyomoto. 2013. "Seasonal and Spring Interannual Variations in Satellite-Observed Chlorophyll-A in the Yellow and East China Seas: New Datasets with Reduced Interference from High Concentration of Resuspended Sediment." Continental Shelf Research 59: 1-9. doi:10.1016/j.csr.2013.03.009.

Zhang, H., Z. Qiu, D. Sun, S. Wang, and H. Yijun. 2017. "Seasonal and Interannual Variability of Satellite-Derived Chlorophyll-A (2000-2012) in the Bohai Sea, China." Remote Sensing 9 (6): 582. doi:10.3390/rs9060582.

Zhang, S. W., Q. Y. Wang, Y. Lü, H. Cui, and Y. L. Yuan. 2008. "Observation of the Seasonal Evolution of the Yellow Sea Cold Water Mass in 1996-1998." Continental Shelf Research 28 (3): 442-457. doi:10.1016/j.csr.2007.10.002. 